\title{
CYSTICERCOSIS OF THE PARASPINAL MUSCLES: A CASE REPORT AND REVIEW OF LITERATURE
}

\section{Nazim Mughal* \\ Nikhat Naaz \\ Deepankar Mishra}

\section{Ajay Srivastava}

Assistant Professor, Dept. of Orthopaedic Surgery, Rajshree Medical College, Bareilly, UP (INDIA) *Corresponding Author

Senior Resident, Dept. of Community Medicine, Rajshree Medical College, Bareilly, UP (INDIA)

Assistant Professor, Dept. of Orthopaedic Surgery, Rajshree Medical College, Bareilly, UP (INDIA)

Assistant Professor, Dept. of Orthopaedic Surgery, Rajshree Medical College, Bareilly, UP (INDIA)

ABSTRACT Introduction: Cysticercosis is a disease of public health importance which causes significant morbidity and mortality in developing countries including India. The clinical presentation of cysticercosis is variable and involves various body tissues. Isolated muscle involvement of cysticercosis is relatively rare. Case Presentation: We report a case of 28 year old female with complaints of mid back pain. Investigations revealed cysticercosis of the para-spinal muscles. Due to non-resolution of symptoms with oral medication, patient was managed surgically and the lesion was removed. Conclusion: Cysticercosis should always be included in differential diagnosis of muscle swelling in countries endemic for Taenia infection. Surgical resection may be required in muscular form of cysticercosis if significant improvement is not observed with conventional oral treatment.

\section{KEYWORDS : Muscular Cysticercosis, Taenia infection}

\section{INTRODUCTION}

Taeniasis which refers to intestinal infection of humans with tapeworms, is caused by 3 main species:- Taenia solium, Taenia saginata and Taenia aciatica. Taenia solium taeniasis is the most common and occurs as a result of ingestion of larval cysts (cysticerci) in undercooked and infected pork. Humans may become intermediate hosts in the life cycle of $\mathrm{T}$. solium after ingestion of its eggs. Infection with Tania solium presents in two forms: Taeniasis and Cysticercosis. Taeniasis occurs as a result of infection with adult tapeworms and cysticercosis occurs due to infection with the larval stages (cysticerci) of the tapeworm. Human cysticercosis has been included in the list of neglected tropical diseases by WHO. Cysticercosis is a disease of public health importance which causes significant morbidity and mortality in developing countries of Asia, Africa and Latin America. The adult tape worm lives in the intestine of humans who may later shed the proglottids containing eggs in faeces. These eggs may later be ingested by pigs where cysticercosis develops in the muscle. Humans will aquire T.solium infection as a result of ingestion of raw beef/pork containing the cysticerci. The clinical presentation of cysticercosis is dependent on number, size, site and stage of lesion. The severity of lesion also depends on the immune response of the host.- Involvement of isolated muscle in cysticercosis is relatively rare and lesser documented. We report a case of muscular form of cysticercosis in the paraspinal muscles.

\section{Case Presentation:}

A 28 year old female presented to Orthopaedics outpatient with complaints of pain in mid back since 8 months and swelling in mid back region since 6 months (Fig 1). The pain was insidious in onset, continuous, dull aching in nature and aggravated on standing, walking, or slight movement. There was no history of trauma, fever, vomiting, headache, dizziness, seizure or any other constitutional symptoms. There was no history of passage of worms in stools. There was no significant past medical history. On physical examination, a swelling of size $4 \mathrm{~cm} \times 5 \mathrm{~cm}$ with firm consistency was observed in mid back para-spinal region on right side. The surface was smooth, margins were ill defined and fluid thrill was absent. Diffuse tenderness was present on mid back right side in para-spinal region. Paraspinal muscle spasm was present. Motor power was 5/5 in both Upper and lower limbs bilaterally. There was no sensory loss. Deep Tendon reflexes were normal. Range of motion of cervical, dorsal and lumbar spine was normal. Rest of the general physical examination and systemic examination was normal.

Investigations were done and the findings were as follows:Hemogram: Hb-11.4g\%, TLC-3900/cmm, DLC: Polys-59, lymphos-33, eosin-05 and mono-03\%, RBC Count4.37millions/UL, Platelet count- 0.85 lakh/cmm, MCV-86.5fl., MCH-24.9pg, MCHC-28.8\%, Random blood sugar-104mg/dl, RFT: Blood Urea- $19 \mathrm{mg} / \mathrm{dl}$, S. creat- $0.42 \mathrm{mg} / \mathrm{dl}$, Serum uric acid$3.2 \mathrm{mg} / \mathrm{dl}$, Serum Electrolytes: S.Sodium-132meq/l, S. Potassium-3.4meq/l, S. Chloride-104meq/L, S. Phosphorus$3.12 \mathrm{mg} / \mathrm{dl}$, S. Calcium-8.67mg/dl, LFT: Serum bilirubin$0.45 \mathrm{mg} / \mathrm{dl}$, direct-0.06mg $/ \mathrm{dl}$, indirect $-0.39 \mathrm{mg} / \mathrm{dl}$, SGOT23U/L，SGPT-18U/L，GGTP-18U/L， S. Alkaline phosphatase74U/L, Total Protein-6.8g/dl, Serum Albumin-4.02g/dl, CReactive protein- $48.1 \mathrm{mg} / \mathrm{L}$, Lipid profile: Total Cholesterol$106.3 \mathrm{mg} / \mathrm{dl}$, Triglycerides $-104 \mathrm{mg} / \mathrm{dl}$, HDL $-48.5 \mathrm{mg} / \mathrm{dl}$, $127 \mathrm{mg} / \mathrm{dl}$, VLDL-30.8mg/dl, Thyroid profile: T3-0.9ng/ml, T4$10.2 \mathrm{micg} / \mathrm{dl}, \mathrm{TSH}-1.67$

Ultrasonography was done and it showed typical appearance of cysticercosis showing central cystic part with scolex visible in the centre of lesion (Fig 2). On MRI, a cystic lesion of size $17 \mathrm{~mm} \times 10 \mathrm{~mm}$ was seen at lower dorsal level in right para median region around posterior para spinal muscles (Fig 3). There was oedema surrounding the lesion. The findings were suggestive of myocysticercosis. Rest of the vertebra and intervertebral discs were normal. Posterior bony elements, facet joints and rest of bilateral neural foramina were normal. MRI of Brain was normal. The patient was initially managed with conservative treatment:- First three days of oral Prednisolone followed by Albendazole $15 \mathrm{mg} / \mathrm{kg} /$ day. Follow up after 2 weeks showed no reduction in swelling and pain was increased with a VAS score of 8/10.

Considering non resolution of symptoms with conservative management, she was planned for surgical intervention. The swelling was excised and her intraoperative and 
postoperative period were uneventful (Fig 4). The patient was discharged the next postoperative day and her subsequent follow up showed improvement in symptoms.

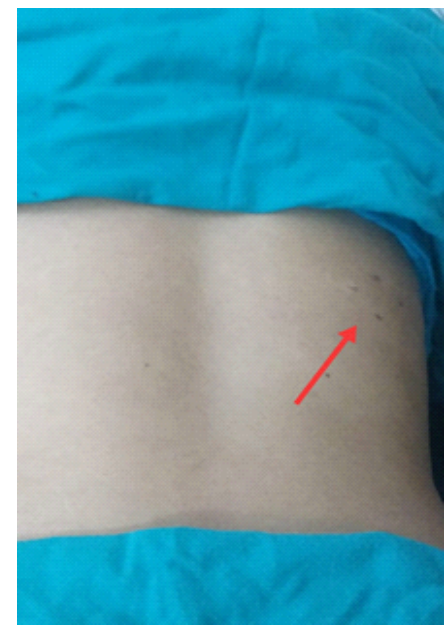

Fig l: Posterior view of patient's back showing a swelling of approx. size $4 \times 5 \mathrm{~cm}$.

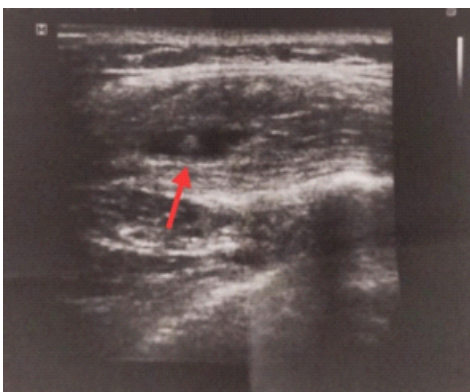

Fig 2: USG showing isolated cystic lesion with well-defined echogenic scolex in the centre.

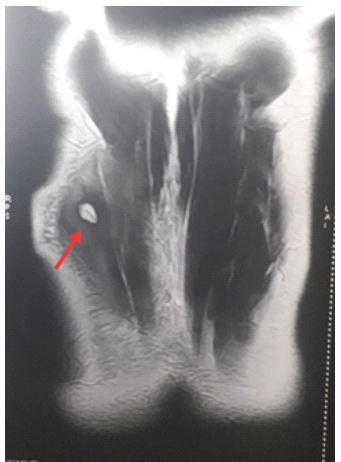

Fig 3 (a) MRI showing a cystic lesion of size $17 \mathrm{~mm} \times 10 \mathrm{~mm}$ around paraspinal muscles.

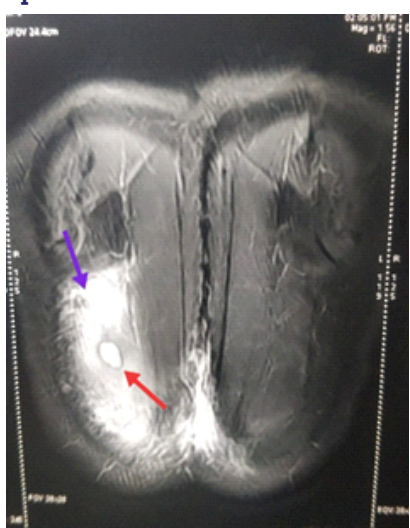

Fig 3(b) MRI showing a cystic lesion of size $17 \mathrm{~mm} \times 10 \mathrm{~mm}$ around paraspinal muscles.

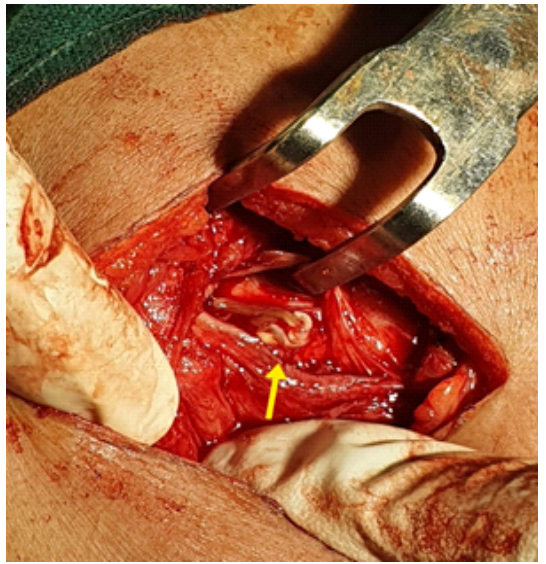

Fig 4: Intra operative image of patient showing scolex.

\section{DISCUSSION:}

Majority (86\%) of the diagnosed cases of taenia solium infection involve the ocular or cerebral region. However, remaining $14 \%$ of presentation mainly involve subcutaneous, cardiac, pulmonary, muscular, hepatic and oral regions.(6) The muscular form of cysticercosis may present as four distinct manifestations:- myalgic or myopathic type, modular or mass like type, abscess type and pseudo hypertrophic type. In the muscular type, there is an intense inflammatory reaction when larva dies. However, in other types, there is a chronic inflammatory reaction due to cyst degeneration and intermittent leakage of cyst fluid in the surrounding structures. (7) Involvement of isolated muscle in cysticercosis is relarively rare. Howevere, in a developing country like India which is endemic for Taenia infection, cysticercosis should be always be kept in the differential diagnosis while evaluating a case of muscle swelling.(8) Table 1 summerizes findings of some of the cases of intramuscular cysticercosis reported in the past.

Imaging modalities like Ultrasonography (USG) and Magnetic Resonance Imaging (MRI) can be used for the diagnosis of soft tissue Cysticercosis. Ultrasonography has described four types of lesions of muscular cysticercosis:- 1 . Cysticercus cyst surrounded by inflammation (resulting from death of larvae), 2.Irregular cyst with very minimal fluid on one side (due to leakage of fluid), 3.Large irregular collection of exudative fluid within the muscle with presence of typical cysticercus cyst containing the scolex, and 4. Calcified cysticercosis. (7)

MRI is the gold standard technique for diagnosis of intarmuscualr cysticercosis (9) and usually shows a well defined soft tissue mass with a cystic lesion along with an eccentric echogenic structure inside suggestive of scolex.(10)

International Task Force for Disease Eradication, 1993 has described Taenia solium cysticercosis to be amenable to control and eradication. However, it still remains a neglected disease due to lack of information about its burden and transmission and due to lack of easy diagnostic tools which can be employed for field use.(2) Moreover, the diagnosis of muscular forms of cysticercosis may be even further delayed or even missed owing to its non specific clinical presentation.(11)

The treatment of cysticercosis is complex and depend upon various factors like site, size, number and stage of cysts. Treatment options may include medications, surgery or watchful waiting.(12) The usual and effective treatment for cysticercosis include Albendazole and Prednisolone. However, in case of isolated skeletal muscle or soft tissue cysticercosis, surgical excision may be required if pain persists with medical therapy alone.(12) 
Table 1: Summary of cases of Muscular cysticercosis

\begin{tabular}{|c|c|c|c|}
\hline $\begin{array}{c}\text { Age / } \\
\text { Gender }\end{array}$ & $\begin{array}{c}\text { Clinical } \\
\text { Presentation }\end{array}$ & Imaging studies & Management \\
\hline $\begin{array}{l}26 / F \\
(13)\end{array}$ & $\begin{array}{c}\text { Non tender } \\
\text { swelling of } \\
\text { size } 5 \times 4 \text { on } \\
\text { left hand for } 1 \\
\text { month }\end{array}$ & $\begin{array}{l}\text { On MRI : cystic } \\
\text { lesion of } 1 \times 1 \mathrm{~cm} \\
\text { with eccentric } \\
\text { scolex along with } \\
\text { edema in } \\
\text { surrounding deep } \\
\text { muscle plane }\end{array}$ & $\begin{array}{l}\text { Albendazole } \\
\text { for } 3 \text { weeks } \\
\text { followed by } \\
\text { surgical } \\
\text { excision of } \\
\text { lesion }\end{array}$ \\
\hline $\begin{array}{c}22 / F \\
(8)\end{array}$ & $\begin{array}{c}\text { Tender soft } \\
\text { swelling of } \\
\text { size } 3.3 \times 2.5 \\
\text { on lateral } \\
\text { aspect of } \\
\text { thigh. }\end{array}$ & $\begin{array}{c}\text { USG: cystic lesion } \\
\text { of size } 23 \times 6 \mathrm{~mm} \text { in } \\
\text { lateral } \\
\text { compartment of } \\
\text { thigh with nodular } \\
\text { scolex and } \\
\text { surrounding edema } \\
\text { suggestive of } \\
\text { myocysticercosis }\end{array}$ & $\begin{array}{c}\text { Albendazole } \\
\text { for } 3 \text { weeks } \\
\text { with } \\
\text { Prednisolone }\end{array}$ \\
\hline $\begin{array}{c}20 \mathrm{yr} / \mathrm{F} \\
(14)\end{array}$ & $\begin{array}{c}\text { Persistent low } \\
\text { back pain for } \\
2 \text { months. On } \\
\text { Physical } \\
\text { Examination: } \\
\text { Tenderness } \\
\text { on left side at } \\
\text { L2/L3 level. }\end{array}$ & \begin{tabular}{|c|} 
USG: well-defined \\
isolated cystic \\
lesion of size 1.8 \\
$\mathrm{~cm} \times 1.2 \mathrm{~cm}$ in the \\
left paraspinal \\
muscles with \\
well-defined \\
echogenic scolex of \\
$3 \mathrm{~mm}$ size with \\
features of \\
surrounding \\
inflammation.
\end{tabular} & $\begin{array}{c}\text { Albendazole } \\
15 \mathrm{mg} / \mathrm{kg} \text { for } 2 \mathrm{l} \\
\text { days. } \\
\text { Prednisolone } \\
\text { 2mg/kg/day. } \\
\end{array}$ \\
\hline $\begin{array}{l}30 / F \\
(15)\end{array}$ & $\begin{array}{c}\text { Pain and } \\
\text { swelling of } \\
\text { anterior right } \\
\text { arm for } 6 \\
\text { months. } \\
\text { Size of } \\
\text { swelling was } \\
3 \mathrm{~cm} \times 2 \mathrm{~cm} \text {. }\end{array}$ & \begin{tabular}{|c|} 
MRI: multi \\
lobulated cystic \\
lesion of size $13 \times$ \\
$8.3 \times 14 \mathrm{~cm} 3$ along \\
with surrounding \\
inflammation \\
suggestive of \\
cysticercosis. MRI \\
brain showed \\
Neurocysticercosis \\
stage IV.
\end{tabular} & $\begin{array}{c}\text { Albendazole, } \\
\text { Prednisolone } \\
\text { and } \\
\text { symptomatic } \\
\text { treatment }\end{array}$ \\
\hline $\begin{array}{c}30 \mathrm{yr} / \mathrm{M} \\
(15)\end{array}$ & $\begin{array}{l}\text { Abnormal } \\
\text { bumpy } \\
\text { growth on } \\
\text { right biceps } \\
\text { muscle for } 2 \\
\text { months. }\end{array}$ & \begin{tabular}{|c|} 
MRI showed \\
disseminated well \\
defined \\
cerebrospinal fluid \\
signal intensity \\
cystic lesions with \\
eccentric \\
hypointense nodule \\
(suggestive of \\
scolex) in the \\
paraspinal \\
muscles, tongue, \\
brain parenchyma \\
and ventricles.
\end{tabular} & $\begin{array}{c}\text { Albendazole } \\
\text { with } \\
\text { Prednisolone. } \\
\\
\end{array}$ \\
\hline
\end{tabular}

\section{CONCLUSION:}

Cysticercosis is a disease of public health importance which causes significant morbidity and mortality in developing countries of Asia, Africa and Latin America. The clinical presentation of cysticercosis is variable and depend on number, size, site and stage of lesion and the immune response of the host. We report a case of isolated cysticercosis of paraspinal muscle. Surgical excision of the lesion was done owing to non response to medical therapy.

\section{Clinical Message:}

Isolated muscular cysticercosis is relatively rare. However, in a country like India which is endemic for Taenia infection, cysticercosis should always be kept in differential diagnosis while evaluating a case of muscle swelling. Surgical resection may be required in muscular form of cysticercosis if significant improvement is not achieved with conventional oral treatment. Consent: The authors certify that they have obtained all appropriate patient consent forms. In the form the patient has given her consent for her images and other clinical information to be reported in the journal. The patients understand that their names and initials will not be published and due efforts will be made to conceal their identity, but anonymity cannot be guaranteed.

Conflict of interest: The author(s) declare that they have no competing interests.

\section{Author's Contribution:}

Patient came to Orthopaedics Outpatient and was seen and managed by first author-Dr Nazim. Later, surgery was done by him on non resolution of symptoms with oral medications. Second Author-Dr Nikhat was involved in manuscript writing, editing and formatting. All authors authors were involved in discussion on treatment options for the patient. The final script was reviewed by all authors.

\section{REFERENCES:}

1. WHO Taeniasis/Cysticercosis [Internet]. 2020 [cited 2020 Aug 22]. Available from: https://www.who.int/news-room/fact-sheets/detail/taeniasiscysticercosis

2. WHO About Taeniasis/cysticercosis [Internet]. WHO. World Health Organization; [cited 2020 Aug 22]. Available from: http://www.who.int/ taeniasis/about disease/en/

3. S Giri, SC Parija. A review on diagnostic and preventive aspects of cystic echinococcosis and human cysticercosis [Internet]. Vol. 2, Tropical parasitology. Trop Parasitol; 2012 [cited 2020 Aug 22]. Available from: https://pubmed.ncbi.nlm.nih.gov/23767016/

4. WHO |Zoonoses: Taeniasis/Cysticercosis [Internet]. WHO. World Health Organization; [cited 2020 Aug 22]. Available from: https://www.who.int/ zoonoses/diseases/taeniasis/en/

5. Nash TE, Neva FA. Recent Advances in the Diagnosis and Treatment of Cerebral Cysticercosis [Internet]. http://dx.doi.org/10.1056/ NEJM 19841 2063112307. Massachusetts Medical Society; 2010 [cited 2020 Aug 31]. Available from: https://www.nejm. org/doi/pdf/ 10.1056/ NEJMl 98412063 112307

6. Coexistence of salivary gland cysticercosis with squamous cell carcinoma of the mandible. Oral Surg Oral Med Oral Pathol Oral Radiol Endodontology. 2007 Mar 1:103(3):e47-50.

7. Vijayaraghavan SB. Sonographic Appearances in Cysticercosis. J Ultrasound Med. 2004 Mar 1;23(3):423-7.

8. Bhardwaj A, Sharma S, Arya A, Kushwaha S, Chaturvedi M. Isolated myocysticercosis: rare presentation in quadriceps muscle. Int J Basic Clin Pharmacol. 2020 Jan 24;9(2):361.

9. P Salgado, R Rojas, J Sotelo. Cysticercosis. Clinical classification based on imaging studies [Internet]. Vol. 157, Archives of internal medicine. Arch Intern Med; 1997 [cited 2020 Sep 2]. Available from: https:// pubmed. ncbi. nlm. nih.gov/9308511/

10. Venkat B, Aggarwal N, Makhaik S, Sood R. A comprehensive review of imaging findings in human cysticercosis. Jpn J Radiol. 2016 Apr;34(4):24l-57.

11. Tripathy SK, Sen RK, Akkina N, Hampannavar A, Tahasildar N, Limaye R. Role of ultrasonography and magnetic resonance imaging in the diagnosis of intramuscular cysticercosis. Skeletal Radiol. 2012 Sep;41(9):1061-6.

12. Kraft R. Cysticercosis: An Emerging Parasitic Disease. Americal Family Physician. 2007;76(1):6.

13. Arjun Agarwal, Cheena Garg, Mohit Agarwal. Myocysticercosis as A Rare Cause of Hand Swelling: A Case Report With Review of Literature. Int J Anat Radiol Surg. 2015;4(3):30-2.

14. Afaq S, Mittal A, Mir RF. Isolated paraspinal muscle cysticercosis diagnosed on ultrasonography in a young patient presenting as low back ache. Int J Med Public Health [Internet]. 2013 [cited 2020 Aug 23];3(3). Available from: /article/291

15. Sud MB, Marwah S, Dubey AB, Gehlawat R. Intramuscular Cysticercosis; 2 Cases. Int J Med Health Res. 2017 Apr 1;3(4):107-9. 